\title{
Ruminoscopy in Cattle (Bos taurus) with Ruminal Lactacidosis - A Rapid and Novel Method to Visualize Rumen Papillary Changes
}

\author{
K. Sasikala ${ }^{1}$, G. Vijayakumar $^{1 *}$, S. Sivaraman ${ }^{1}$ and G.A. Balasubramaniam ${ }^{2}$ \\ ${ }^{1}$ Department of Veterinary Clinical Medicine, ${ }^{2}$ Department of Veterinary Pathology, \\ Veterinary College and Research Institute, Namakkal 637 002, Tamilnadu Veterinary and \\ Animal Sciences University, Chennai, India \\ *Corresponding author
}

\section{A B S T R A C T}

\section{Keywords}

Cattle, Ruminal acidosis, Endoscopy, Papillary changes

Article Info

Accepted:

22 April 2018

Available Online:

10 May 2018
Seventy eight Jersey and thirty two Holstein Friesian cross bred cattles were reported with the history of carbohydrate engorgement. Rumen fluid $\mathrm{pH}$ was less than 5 in all the animals. Endoscopy was performed by using Olympus flexible video endoscope. Animals were physically restrained without sedation. On endoscopy yellowish to brown coloured fluid could be visualized upon entering through relaxed lower oesophageal sphincter. The rumen fluid was lavaged out and irrigation of rumen was done to facilitate the ruminoscopy. The endoscope tip placed on the dorsal and ventral sac of the rumen revealed greyish to light brown coloured cornified epithelium and necrosis. In some places it was peeled off easily and dark, hemorrhagic surface was found beneath, although no such changes were noticed in the reticulum. Endoscopic guided biopsy revealed massive vacuolar degeneration with varying nuclear changes of squamous epithelium in rumen and reticulum on histopathology.

\section{Introduction}

Endoscopic procedures of the bovine fore stomach are described rarely in literature and are limited in respect to the reticulum, considering the surface of ruminal mucosa (Breitner et al., 1998) and the motility of the reticulo-omasal opening (Kelly et al., 1991). Nevertheless rumen diseases of ruminating animals and milk fed calves in dairy herds are very common and cause enormous economic losses (Dirksen, 2008). Ruminant animals are adapted to digest and metabolize predominantly forages. Ruminal acidosis is increasingly recognized as a significant disorder in ruminants that increases the morbidity and mortality of animals, especially for dairy cattle and sheep ( $\mathrm{Xu}$ and Ding, 2011). It is most commonly caused by the sudden ingestion of toxic doses of carbohydrate-rich feed, such as grain which increases lactic acid production and ends in chemical rumenitis. Nowadays higher grain diets are fed to dairy cattle to increase milk production. It is well known that high grain diet feeding affects ruminal fermentation, characteristics and structure of the contentassociated rumen microbial population 
(Metzler-Zebeli et al., 2013; Petri et al., 2013; Zened et al., 2013).

The high concentration of lactic acid in the rumen causes chemical rumenitis (Constable et al., 2017). Rumen mucosal damage is another consequence associated with rumen acidosis (Nocek, 1997). The rumen mucosa plays a vital role in whole-animal energy balance through the transport and metabolism of rumen-derived volatile fatty acids (VFAs) (Baldwin, 1998). In addition, the rumen epithelium acts as a protective barrier between the rumen environment and portal circulation (Graham and Simmons, 2005). Ruminal acidosis has been associated with a high incidence of ruminal wall lesions and the condition of ruminal parakeratosis. The characteristics of ruminal parakeratosis include accumulated layers of keratinized, nucleated squamous epithelial cells and excessive sloughing of the epithelium (Hinders and Owen, 1965; Bull et al., 1965).

Historically, rumen mucosal experimental studies have involved either slaughter of animals (Naeem et al., 2012), or rumen cannulation, also referred to as fistulation (Steele et al., 2011b). Both these methods are expensive, time consuming and not suitable for animals that are to be retained for breeding. Moreover, slaughter of the animal is not feasible for time-course studies as serial sampling of the same animals are impossible. Serial sampling can be undertaken using rumen cannulation, which allows long term, minimally invasive access to the rumen (Hecker, 1969), however, this process is not convenient for studies requiring large numbers of animals. While cannulation is currently the conventional method for studies that require sequential sampling of rumen contents, endoscopic biopsies are a viable alternative. In domestic ruminants endoscopy via a ruminal cannula has been used for evaluation of the rumen (McBride et al., 1983), and for sampling to determine gene expression (Suominen et al., 1998; Taylor Edwards et al., 2010; Steele et al., 2015). An alternative method of obtaining tissue for biopsy studies is via oral endoscopy. In calves, oral endoscopy has been evaluated as a tool to describe the visible structures of the rumen by Franz et al., (2006).

Nasoruminal endoscopy is very challenging in calves, sheep and goats because endoscopes that are sufficiently small to pass through the nasal passages are usually not long enough to reach the rumen. Ororuminal endoscopy using a mouth gag has been infrequently performed because of the risk of damage to the instrument as well as poor visualization of the rumen and reticulum. However, removal of rumen contents using a siphon and lavage method improved visualization ability (Constable et al., 2017). The objective of this study was to explore the viability of nasoruminal endoscopy for evaluation of rumen epithelial changes in ruminal acidosis, biopsy of rumen papillae and evaluating the biopsies obtained via this method in histopathology.

\section{Materials and Methods}

\section{Experimental design}

Seventy eight Jersey cross bred and thirty two Holstein Friesian cross bred cattle (110 cattle) brought to Teaching Veterinary Clinical Complex (TVCC), Veterinary College and Research Institute, Namakkal with the history of carbohydrate engorgement during the study period of 2015-16 were included in the study. Among these 110 animals 3 were male and 107 were female. The animals studied were between $2-8$ years old and weighed 200 to $350 \mathrm{~kg}$. Animals brought for routine checkup and deworming during this period served as a control group for endoscopic evaluation of the rumen. 


\section{Endoscopy}

All the cattle were physically restrained without sedation. Rumenoscopy was performed using (Olympus ${ }^{\mathrm{TM}}$ GIF V70; Olympus Corporation, Japan) flexible video endoscope with a diameter of $8 \mathrm{~mm}$ and a usable length of $150 \mathrm{~cm}$ that featured a channel for instruments (diameter $4 \mathrm{~mm}$ ) and navigation system allowing the endoscope to be moved in two directions (upward $180^{\circ}$ and downwards $100^{\circ}$ ). Every four centimeters of the endoscope was marked with fine white lines.

The instrument was equipped with a halogen light source, an irrigation system, an insufflation system and recording devices. The use of image and data archiving system allowed digital recording of the endoscopic findings during examination. Nasogastric endoscopic procedure of passing the endoscope up to oesophagus as described by Franz and Baumgartner (2002) and up to reticulum as described by Sasikala et al., (2017) was followed. Insufflation with air, irrigation with water and suction enhanced the visualization of rumen and reticulum during endoscopic procedure.

Where there was abundant rumen content in ruminal acidosis, visual examination of the ruminal mucosa was not possible and the rumen was therefore evacuated by using stomach tube. For flushing approximately 15 $30 \mathrm{~L}$ of water was drenched with the help of rumen rehydration pump.

\section{Endoscopic biopsy}

Biopsy forceps was passed through the working channel of the video endoscope and the tissue samples collected were stored in 10 per cent formalin and subjected to the histopathological examination as described by Bancroft and Gamble (2008).

\section{Results and Discussion}

Evacuation of sour rumen contents and lavaging was necessary in all the cattle for proper visualization of rumen and reticulum. In all the cattle the rumen $\mathrm{pH}$ was less than 5 on rumen fluid examination.

Endoscope was passed through the nasogastric route into the rumen. Animals were physically restrained without sedation. On endoscopy neither reticulum nor rumen could be visualized. Yellowish to brown coloured fluid could be visualized upon entering through relaxed lower oesophageal sphincter (Fig. 1). The rumen fluid was lavaged out to facilitate the visualization of reticulo-rumen and it is an alternative to rumenotomy to prevent further production of lactic acid in rumen. The contents were milkish white, sour odoured and watery in nature suggestive of fermentation. Out of 110 cases 28 animals were in recumbent position.

So in remaining less severe cases which were in standing position irrigation of the rumen was done by using rumen rehydration pump. Water was pumped into the rumen up to the visible distension of left paralumbar fossa and then the rumen is allowed to empty by gravity flow. The rumen could be partially emptied by 5 - 10 irrigations for better visualization during the endoscopic procedure. None of the animal developed aspiration pneumonia after this procedure. After lavaging and irrigation of the rumen, endoscope was passed into the reticulo-rumen. The surface of the ruminal mucosa (colour, smoothness and shine) was evaluated endoscopically by placing the tip of the endoscope on the dorsal and ventral sac of the rumen. The cornified epithelium was greyish to light brown coloured and necrosed (Fig. 2 and 3). In some places it was peeled off easily and dark, hemorrhagic surface was found beneath (Fig. 4), although no such changes were noticed in the reticulum. All 
these changes were restricted to the ventral sac of rumen.

Endoscopic guided biopsy on histopathology revealed massive vacuolar degeneration of squamous epithelium (Fig. 5) and severe degenerative changes of squamous epithelium and their fusion in reticulum (Fig. 6) and massive vacuolar degeneration of squamous epithelium resulting in displacement of their nucleus in rumen (Fig. 7).

Ruminal acidosis is a common problem in large animal medicine. This produces severe mucosal damage of the rumen wall. These rapid structural changes of the epithelium increase the animal's susceptibility to microbial infection and alter rumen metabolism and nutrient absorption (Plaizier et al., 2008), further affects its production performance and ends in huge economic loss. Endoscopy, the inspection of bodily cavities by means of optical devices, was adopted from human medicine and has enjoyed growing importance in veterinary medicine in recent years. Today, in the fields of equine and small animal medicine, it represents an essential method of examination, aiding diagnosis and serving as a means of therapy in connection with minor surgical intervention as well (Franz, 2008).

Constable et al., (2017) found thin and porridge like rumen content with a typical odour of fermentation on necropsy of ruminal acidosis cases. The cornified epithelium was mushy and easily wiped off, left a dark, hemorrhagic surface beneath.

The wall of the rumen and reticulum had widespread gangrene and thickened. Similar changes were reported in live clinical cases during ruminoscopic procedure. This change may be caused by the production of excess lactic acid and restricted to the ventral sac of the rumen. Lavaging and irrigation of rumen contents in less severe acidosis cases and in standing animals was reported by Constable et al., (2017). In these animals, lavage and / or irrigation with water and subsequent siphoning were needed for visualization of rumen and reticulum. Although the compound stomach of the cattle cannot be compared with the stomachs of monogastric animals, withholding feed and flushing of the stomach were widely used in horses, small animals and pigs before gastroscopy (Franz et al., 2004; Kraft, 1993; Mackin et al., 1997; Vatistas et al., 1997). Breitner et al., (1998) and Franz et al., (2006) advocated flushing of rumen before endoscopy via the artificial rumen fistula or by using an orally introduced stomach tube.

Watching for any kind of movement of organs or specific anatomical structures was one of the greatest advantages of endoscopic examination when comparing this to other imaging techniques such as radiography and computer tomography (Kraft, 1993; Mayrhofer et al., 2004). Another important aspect was the opportunity to visualize the mucosal surface directly, enabling colour, smoothness and brightness in addition to pathological mucosal alterations to be evaluated (Franz et al., 2000). In the presence of pathology, direct visual examination of the reticulo-ruminal mucosa and assessment of contractions of the rumen and reticular groove might aid in the diagnosis of diseases of the reticulo-rumen and determination of the extent of pathological alterations. As such, endoscopy of reticulo-rumen could be a helpful diagnostic tool as part of the clinical examination (Breitner et al., 1998).

Breitner et al., (1998) and Franz et al., (2006) reported that ruminoscopy via the oral approach was not satisfactory especially in ruminating calves when compared to the rumen fistula technique. However in the present study endoscopy of reticulo-rumen via the nasal route was found to be satisfactory and well tolerated in all cattle. 


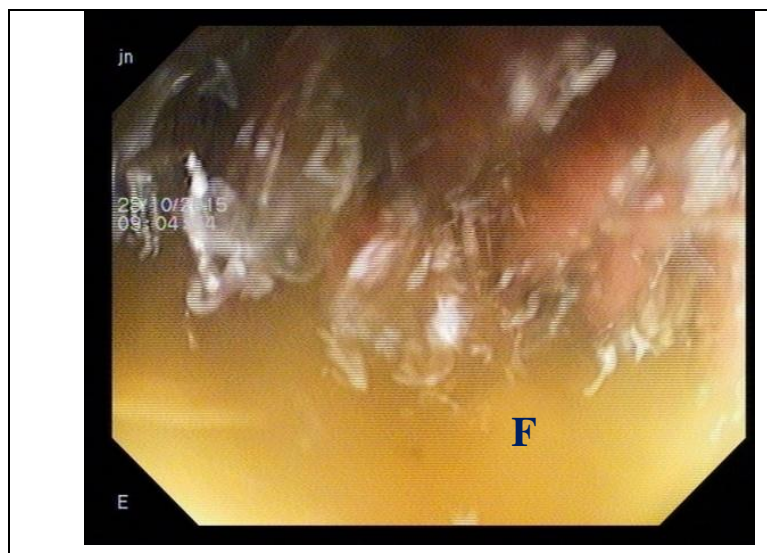

Fig.1 Fluid filled reticulum - F - Rumen fluid

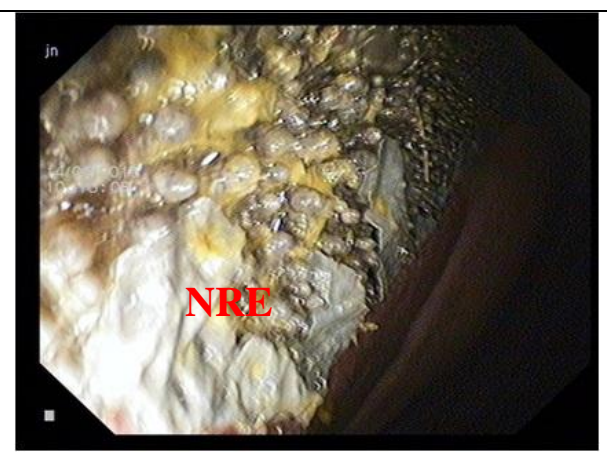

Fig.3 Necrosed rumen epithelium (NRE) Rumen (Ru)

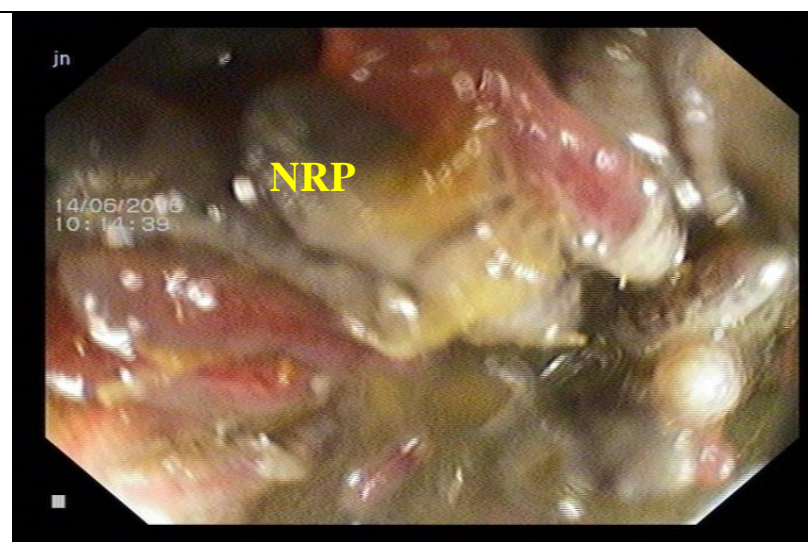

Fig.2 Necrosed rumen papillae (NRP)

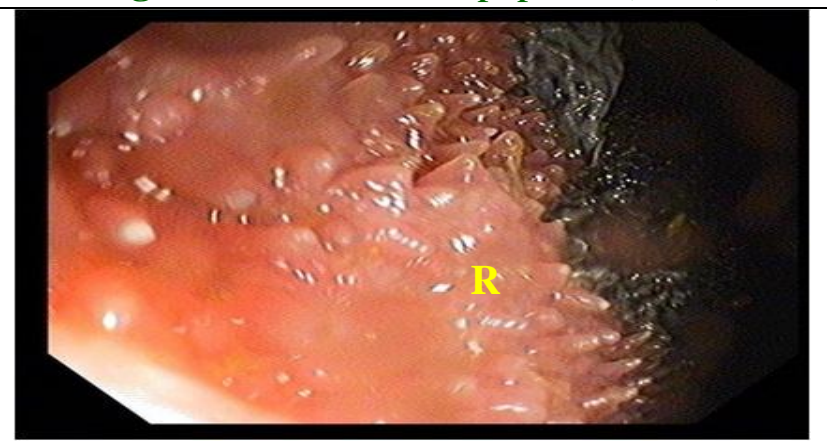

Fig.4 Sloughed epithelium left haemarrhagic surface - Rumen (R)

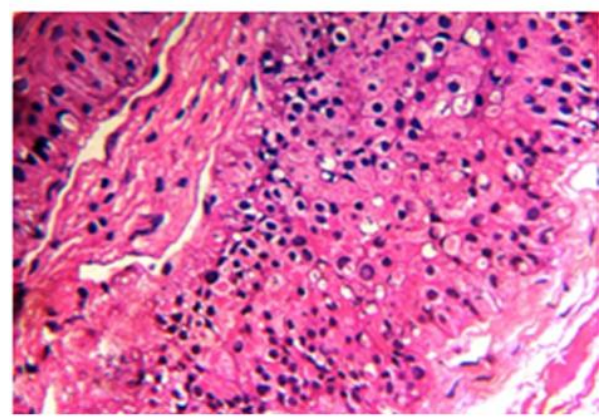

Fig.5 Histopathology: Reticulum showing massive vacuolar degeneration of squamous epithelium (H \& E stain; 40 x)

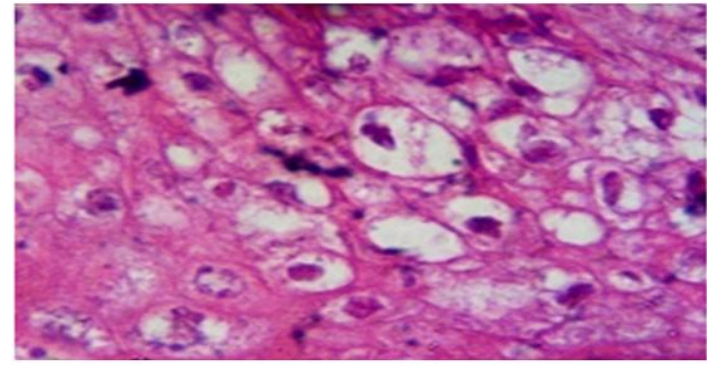

Fig.6 Histopathology - Reticulum showing massive degenerative changes of the squamous epithelium and their fusion (H \& E stain; $100 \mathrm{x}$ )

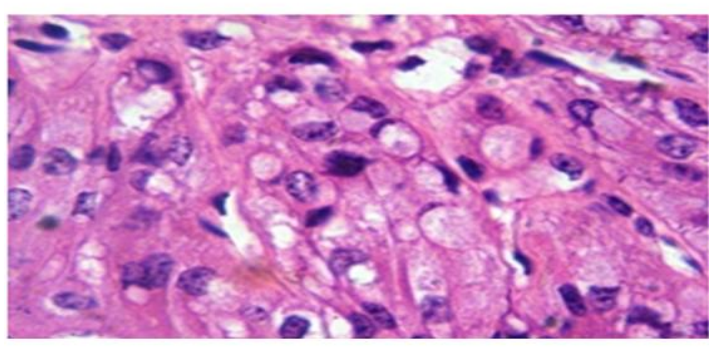

Fig.7 Histopathology: Rumen showing massive vacuolar degeneration of squamous epithelium resulting in displacement of their nucleus $(\mathrm{H} \&$ E stain; $100 \mathrm{x}$ ) 
This was supported by the observations of McRae et al., (2016) who reported that endoscopy via oral route in sheep offered an attractive and cost effective approach to repeated rumen biopsies compared to serial slaughter or use of cannulated animals.

Massive vacuolar degeneration of squamous epithelium in reticulum, severe degenerative changes of squamous epithelium with varying nuclear changes and massive vacuolar degeneration of squamous epithelium resulting in displacement of their nucleus in rumen were observed in histopathological study in cattle with ruminal lactacidosis. Ruminal parakeratosis, erosion and ulceration of ruminal epithelium (Garry, 2002), extensive sloughing of the stratum corneum (Steele et al., 2011a), denudation, discontinuity of squamous epithelium, hydropic degeneration of epithelial cells of ruminal papillae were noticed in cattle with ruminal lactacidosis.

Histopathological changes observed in the present study were in agreement with the above reports (Garry, 2002; Steele et al., 2011a).

To our knowledge, this is the first study to demonstrate such a rapid alteration of the ruminal epithelium in association with ruminal acidosis in live clinical cases through nasogastric endoscopy.

Endoscopy is boon to veterinary medicine in large animal practice for early detection of rumen papillary changes after grain feeding and endoscopic guided biopsy aids in diagnosis of microstructural changes in rumen papillae. Further research is needed in this area to develop strategies to enhance gastrointestinal adaptation in grain-fed ruminants, which will improve their digestive and absorptive capacity and result in improved animal productivity and well-being.

\section{Acknowledgements}

The authors are thankful to the Dean, Veterinary College and Research Institute, Namakkal for the facilities provided during the study.

\section{Conflict of interest}

None of the authors have any conflict of interest to declare.

\section{References}

Baldwin, R.L.V.I. 1998. Use of isolated ruminal epithelial cells in the study of rumen metabolism. J. Nutr., 128: 293S$296 \mathrm{~S}$.

Bancroft, J.D. and Gamble, M. 2008. Theory and practice of histological techniques. $6^{\text {th }}$ Edn., Churchill Livingstone, London. pp: 75-82.

Breitner, W., Guthle, U. and Gentile, A. 1998. Diagnosis, therapy and prognosis of rumen acidosis in dairy calf (Bos taurus): Evaluation of 64 calves. Pract. Vet., 79: 323-332.

Bull, L.S., Bush, L.J., Friend, J.D., Harris, J.R. and Jones, E.W. 1965. Incidence of ruminal parakeratosis in calves fed different rations and its relation to volatile fatty acid absorption. J. Dairy Sci., 48:1459-1466.

Constable, P. D., Hinchcliff, K. W., Done, A. H. and Grunberg, W. 2017. Veterinary Medicine. A textbook of the diseases of cattle, horses, sheep, pigs and goats. $11^{\text {th }}$ edn., W.B. Saunders Elsevier, Philadelphia. pp. 482-490.

Dirksen, G., 2008. Krankheiten der Verdauungsorgane und der Bauchwand. In: Dirksen, G., Grunder, H. D. and Stober, M. (eds.): Innere Medizin und Chirurgie des Rindes, Vol. 4. Parey, Berlin, Germany, pp. 455-468. 
Franz, S. and Baumgartner, W. 2002. A retrospective study of oesophageal endoscopy in cattle (Bos taurus) and oesophagoscopy for diagnosis of mucosal disease. Vet. J., 163: 205-210.

Franz, S., Gentile, A. and Baumgartner, W. 2006. Comparision of two ruminoscopy techniques in calves (Bos taurus). Vet. J., 172: 308-314.

Franz, S., Kahlbacher, H. Schuh, M. and Schmerold, I. 2004. Oesophagogastroduodenoscopy in pigs technology, method, indications. Berlin. Munchener Tierarztliche, 117: 153-159.

Franz, S., Konig, M., Gasteiner, J. and Baumgartner, W. 2000. Laparoscopy: Indications and pathological findings. Wiener. Tierarztliche., 87: 163-172.

Franz. S., 2008. Importance of endoscopic techniques for diagnosis and therapy in ruminants. XXV. Jubilee World Buiatrics Congress. pp. 33-36.

Garry, F. B., 2002. Indigestion in ruminants. In: Smith, B. P., editor, Large animal internal medicine. Mosby Inc., St. Louis, Baltimore. pp. 722-747.

Graham, C. and Simmons, N.L. 2005. Functional organization of the bovine rumen epithelium. Am. J. Physiol. Regul. Integr. Comp. Physiol., 288(1):R173-R181.

Hecker, J.F., 1969. A simple rapid method for inserting rumen cannulae in sheep. Aus. Vet. J., 45, 293-4.

Hinders, R.G. and Owen, F.G. 1965. Relation of ruminal parakeratosis development to volatile fatty acid absorption. J. Dairy Sci., 48:1069-1073.

Kelly, J.M., Froetschel, M.A., Croom, W.J., Hagler, W.M. and McBride, B.W. 1991. Effects of a parasympathomimetic agent, slaframine on reticulo-omasal orifice function. Can. J. Anim. Sci., 71: 321-326.

Kraft, W., 1993. Endoscopy. Tierarztliche, Schattauer, Stuttgart, Germany.
Mackin, A.J., Friendship, R.M., Wilcock, B.P., Ball, R.O. and Ayles, H.L. 1997. Development and evaluation of an endoscopic technique permitting rapid visualisation of the cardiac region of the porcine (Sus scrofa domesticus) stomach. Can. J. Vet. Res., 52: 19481950.

Mayrhofer, E., Francis, S., Shepherd, R., Berger, K. R., Palme, K., Mosti, E., Joachim, A. and Mosti, K. 2004. Diagnostic tests in veterinary medicine through the ages - presented at selected examples. Vienna Tierarztliche., 26-42.

McBride. B. W., Berzins, R., Milligan, L. P. and Turner, B. V. 1983. Development of a technique for gastrointestinal endoscopy of domestic ruminants. Can. J. Anim. Sci., 63: 349-354.

McRae, K.M., Schultz, M., Mackintosh, C.G., Shackell, G.H., Martinez, M.F. and Knowler, K.J. 2016. Ovine rumen papillae biopsy via oral endoscopy - A rapid and repeatable method for serial sampling. New Zealand Vet. J., 64: 174-178.

Metzler-Zebeli, B. U., Schmitz-Esser, S., Klevenhusen, F., PodstatzkyLichtenstein, L., Wagner, M. and Zebeli, Q. 2013. Grain-rich diets differently alter ruminal and colonic abundance of microbial populations and lipopolysaccharide

in goats. Anaerobe, 20, 65-73.

Naeem, A., Drackley, J.K., Stamey, J. and Loor, J.J. 2012. Role of metabolic and cellular proliferation genes in ruminal development in response to enhanced plane of nutrition in neonatal Holstein calves. J. Dairy Sci., 95, 1807-20.

Nocek, J.E. 1997. Bovine acidosis: Implications on laminitis. J. Dairy Sci., 80:1005-1028.

Petri, R. M., Schwaiger, T., Penner, G. B., Beauchemin, K. A., Forster, R. J. and McKinnon, J. J. 2013. Changes in the 
rumen epimural bacterial diversity of beef cattle as affected by diet and induced ruminal acidosis. Appl. Environ. Microbiol. 79, 3744-3755.

Plaizier, J.C., Krause, D.O., Gozho, G.N. and McBride, B.W. 2008. Subacute ruminal acidosis in dairy cows: The physiological causes, incidence and consequences. Vet. J., 176:21-31.

Sasikala, K., Vijayakumar, G., and Balasubramaniam, G.A., 2017. Endoscopic Evaluation of Reticulum in Cattle - A Preliminary Study. Indian Vet. J., 94 (05): 79 - 80.

Steele, M. A., Croom, J., Kahler, M., Alzahal, O., Hook, S. E., Plaizier, K. and McBride, B. W. 2011a. Bovine rumen epithelium undergoes rapid structural adaptations during grain-induced subacute ruminal acidosis. Am. J. Physiol. Regul. Integr. Comp. Physiol., 300: R1515-R1523.

Steele, M.A., Dionissopoulos, L., AlZahal, O., Doelman, J. and McBride, B.W. 2011b. Rumen epithelial adaptation to ruminal acidosis in lactating cattle involves the coordinated expression of insulin-like growth factor-binding proteins and a cholesterolgenic enzyme. J. Dairy Sci., 95, 318-27.

Steele, M.A., Schiestel, C., AlZahal, O., Dionissopoulos, L., Laarman, A.H., Matthews, J.C. and McBride, B.W. 2015. The periparturient period is associated with structural and transcriptomic adaptations of rumen papillae in dairy cattle. J. Dairy Sci., 98, 2583-95.

Suominen, A.H., Glimm, D.R., Tedesco, D., Okine, E.K., McBurney, M.I. and Kennelly, J.J. 1998. Intestinal nutrientgene interaction: the effect of feed deprivation and refeeding on cholecystokinin and proglucagon gene expression. J. Anim. Sci., 76, 3104-13.

Taylor-Edwards, C.C., Burrin, D.G., Matthews, J.C., McLeod, K.R., Holst, J.J. and Harmon, D.L. 2010. Expression of mRNA for proglucagon and glucagon-like peptide-2 (GLP-2) receptor in the ruminant gastrointestinal tract and the influence of energy intake. Domestic Anim. Endocrinol., 39, 18193.

Vatistas, N. Snyder, J.R. and Johnson, B. 1997. Adult stomach and duodenum. In: Traub-Dargatz, JL and Brown, CM. Equine endoscopy $\left(1^{\text {st }}\right.$ Edn.) Mosby, St. Louis, PP: 172-186.

$\mathrm{Xu}$, Y. and Ding, Z. 2011. Physiological, biochemical and histopathological effects of fermentative acidosis in ruminant production: a minimal review. Spanish J. Agri. Res., 9(2), 414-422.

Zened, A., Combes, S., Cauquil, L., Mariette, J., Klopp, C. and Bouchez, O. 2013. Microbial ecology of the rumen evaluated by 454 GS FLX pyrosequencing is affected by starch and oil supplementation of diets. FEMS Microbiol. Ecol., 83, 504-514.

\section{How to cite this article:}

Sasikala, K., G. Vijayakumar, S. Sivaraman and Balasubramaniam, G.A. 2018. Ruminoscopy in Cattle (Bos Taurus) with Ruminal Lactacidosis - A Rapid and Novel Method to Visualize Rumen Papillary Changes. Int.J.Curr.Microbiol.App.Sci. 7(05): 3112-3119. doi: https://doi.org/10.20546/ijcmas.2018.705.363 